\title{
The Open Innovation Paradigm: from Outsourcing to Open-sourcing in Shenzhen, China
}

\author{
Valérie Fernandez ${ }^{1}$, Gilles Puel ${ }^{2 *}$, Clément Renaud ${ }^{1}$ \\ 1 Telecom ParisTech, UMR I3 \\ 2 University de Toulouse, LEREPS \\ *Corresponding Author, Email: Gilles.Puel@univ-tlse2.fr
}

Received: March 02, 2016; Accepted: May 30, 2016

Key words: Open innovation, New urban places, Makers, shanzhai, Shenzhen

\begin{abstract}
Having once been the headquarters of 'Made in China,' Shenzhen's industry is currently undergoing profound change. The appearance of new urban places for technological innovation is reviving the ageing industrial processes of this manufacturing city. It is supposed to transform Shenzhen into the Silicon Valley of hardware. Two groups, one local, the shanzhai community made up of entrepreneurs and companies historically based on a strategy of imitating highend products, and the other, a more international maker community, are thought to be the main drivers of this change using values of 'open innovation'. The building of this ecosystem relies largely on practices associated with being open-source. Like in California, open innovation contributed to the creation of resources for the development of a vast high-tech industry. This ethnographic field study shows how, while both communities, the international makers and the shanzhai, draw on open innovation, they do not have the same values. For the shanzhai, open innovation means total deregulation and a kind of coopetition that poorly masks fierce competition. For the makers, open innovation does not entirely eliminate the classic tension between 'open' and 'closed' commons in the world of makers. These two communities still rarely collaborate.
\end{abstract}

\section{INTRODUCTION}

Having once been the headquarters of 'Made in China,' Shenzhen's industry is currently undergoing profound change. The appearance of new urban places for technological innovation is reviving the ageing industrial processes of this manufacturing city.

The new 'Made in China' plan, first suggested by experts (Li, 2014) and a few academics (Lindtner, 2014, 2015), is intended to transform Shenzhen into the Silicon Valley of hardware. Two groups, one local, the shanzhai ${ }^{\mathrm{i}}$ community made up of entrepreneurs and companies historically based on a strategy of imitating high-end products, and the other, a more international manufacturing community, are thought to be the main drivers of this change using values of 'open innovation' (Chesbrough \& Bogers, 2014). This idea of rebooting 'Made in China' is widely present on the Internet and, of course, has the support of the Chinese government (as demonstrated in Zhongguo Zhizao 2025).

While both communities, the international makers and the shanzhai, draw on open innovation, they do not have the same goals or the same values. For 
the shanzhai, open innovation means total deregulation and a kind of coopetition that poorly masks fierce competition. For the makers (Anderson, 2012), open innovation does not entirely eliminate the classic tension between 'open' and 'closed' commons in the world of makers (Garnier, 2014). These two communities, while both located in Shenzhen because of the advantages the city offers, still rarely collaborate.

The present study analyzes the dynamics of innovation in these communities, which are situated in this territory and in 'third places' (such as the shanzhai cluster, manufacturing 'fablabs' and 'excubators'). Each of these places incorporates a facet of open innovation and extends the frontiers of the open innovation paradigm, all while reaffirming the situated nature of open innovation. The argument advanced here is that there is truly a geography of innovation, which means that the same concept of open innovation has different economic (and social) realities depending on the territory in which it is situated.

This study, based on extended field research, focuses primarily on describing the models of open innovation in the Shenzhen electronics cluster. The first section presents the concepts involved in open innovation and the second section, the relationship between open innovation and the business strategies and the characteristics of the society, the region, and the organizations involved. The third analyzes the electronics cluster's history and changes over time and the various models of open innovation places that have developed in Shenzhen. The article concludes with a more detailed discussion of our findings about the various configurations of groups working in innovation.

\section{FRAMEWORK: THE BROAD PARADIGM OF OPEN INNOVATION}

This research addresses the subject of open innovation, its models and its different variations over time and in different regions.

\subsection{From open innovation to open source}

The 'open innovation' paradigm described in the seminal work of Chesbrough (2003), referring to strategies of $R \& D$ coopetition, externalization and partnerships, gained currency among researchers at the turn of the millennium. Over the next ten years, the concept took on a broader meaning that was no longer limited to the market. It came to be understood as a combination of an innovation model based on cooperation between firms (compatible with a market economy and new economic models) and a societal model, embodied primarily in the open-source software movement and more generally the spirit of ODOSOS (Open Data, Open Source, Open Standards) (Chesbrough \& Bogers, 2014; West et al., 2014).

This broadening of the open innovation paradigm occurred also within the "spatial turn" movement (Dale \& Burrell, 2008; Van Marrewijk \& Yanow, 2010; Warf \& Arias, 2008), which examines issues through their anchoring in a given geographical space, the capital (spatial, social and cognitive) in those spaces (Bathelt, Malmberg, \& Maskell, 2004), and 'third places' (Oldenburg, 1989). 


\subsection{Third places and open production: hacker spaces and 'fablabs'}

With the generalization of digital manufacturing equipment and networks for exchanging content, the appropriation of open production triggered by open-source has spread to hardware, now known as 'open hardware.' Rapid digital prototyping enabled bottom-up innovation, allowing the market to trigger industrial production and even financing processes based on participative funding platforms such as crowdfunding. In broader terms, these new trends, boosted by urban production spaces ('fablabs') (Gershenfeld, 2005) and technological experimentation (hacker spaces), can be seen as a form of technological re-appropriation by urban users. Beyond the industrial planning of smart cities, a "fab city" was envisioned as 'a city where citizens could have access to a new array of infrastructures, including public 'fablabs' with close ties to private initiatives ${ }^{\mathrm{ii}}$.

\subsection{New innovation ecosystems}

Digital technologies, as networks and as production tools, and open hardware culture have helped expand the spaces of "innovation by doing". They enable, accelerate and concretize initiatives in prototyping that involve co-construction and/or collaboration between different actors in the innovation process. For example with open hardware, the design and the functioning of each component are documented and available online. This facilitates skills transfer and sharing, and the reconfiguration of value chains among individuals and/or companies. The traditional image of the industrial cluster, envisaged as an 'organized market' (Kogut, 2000) within a territory of various actors who complement each other in the production chain, thus becomes enriched, as does the transfer and complementarity of skills (Dyer \& Nobeoka, 2000; Nahapiet \& Ghoshal, 1998). This traditional image of the cluster then gives way to new actors: to people and organisational configurations such as 'third places', on the frontier between market and nonmarket economies.

\section{STUDY DESIGN}

The innovation economy is built around the circulation of so-called intangible assets (ideas, designs, creative skills and so on.) that constitute the intellectual capital of economic actors (individuals, businesses and manufacturing) (Dumay \& Cuganesan, 2011). Recent research using a relational view of economic actors (Bathelt \& Glückler, 2011) has called into question econometric approaches (OECD, 2013) by showing the importance of non-economic activities in increasing businesses' productivity (Corrado et al., 2014).

To analyze the dynamics of open innovation driven by spaces ${ }^{\mathrm{iii}}$ and 'third places,' this study therefore adopted a relational perspective. We consider that a given region's ability to innovate is based on situated processes of creation and knowledge transfer and on its ability to bring together local actors as well as other actors with complementary activities outside the region. 
This study examines both places, which are synapses of a physical and virtual network for the creation of intellectual capital, and the key actors in these places, as nodes of the network.

Fieldwork was done during two periods. In the first, from June to September 2012, a field study ${ }^{\text {iv }}$ was conducted on shanzhai telephones and the geography of Shenzhen companies who had driven this mode of innovation based on reverse engineering. Conducted in partnership with China Unicom, the purpose of this first phase was to analyze the ecosystem of the shanzhai telephone, the business models of the companies who make these phones, the reasons for their success, their limitations, and the new dynamics at work in 2013 with the arrival of shanzhai smartphones.

Next, a period of desk research identified three meta-models of innovation places. The key places and actors in these meta-models were then identified by mapping the physical and relational spaces. This mapping sought to determine the emblematic character of the places for each model.

The first model identified a group of 'third places' mentioned in the relevant literature, namely co-working spaces, hackerspaces, and a hybrid of the previous two. These spaces are those of 'makers' with their media events, such as the Maker Faire and the Maker Carnival. As the analysis of these places has been discussed elsewhere (Renaud, Fernandez, \& Puel, 2015), the present paper will only briefly touch on these aspects.

The second model identified was that of an incubator/accelerator for hardware startups (such as Seeed Studio and Hax). The main goal of organizations with this model is to support creation and business development in the open source environment. These places serve as bridges between the West and China.

The third meta-model identified was the cluster model with its various forms, such as the shanzhai where innovation is often confused with intellectual property violations. Examples are Huaqiangbai, the giant cluster of electronics suppliers and a synapse between the worlds of shanzhai and makers, and Bao'An, a creative cluster and an emblematic place for the proposed transformation of Shenzhen into the Silicon Valley of hardware.

These models were then tested in the second period of fieldwork of participatory observation from December 2014 to February 2015 in Shenzhen. For each of these places, fieldwork was conducted on site, including visits, an inventory of the objects and machines present, and interviews with the key actors of these places. Using the person-to-person method of the Chicago School (Blanchet \& Gotman, 2007), we gradually validated or enriched our study design through interviewing these networks' key informants.

Twenty-seven key informants were interviewed in nine different places, covering all three models observed. For the clusters, which we consider here as one space, several different companies within them were interviewed. Participants were questioned about the place's value proposition and business model, the sociological profiles of users for models one and two, relations with local and international actors (institutions, users, competitors, etc.), the image of open source, and the actual practices of open source in their daily work context. These site visits were supplemented by meetings with several important people in the innovation ecosystem in China. ${ }^{v}$ 


\section{ECOSYSTEM DYNAMICS IN SHENZHEN}

The history of Shenzhen's territory has been marked by three periods. First, it was the 'factory' for Western countries that outsourced the manufacturing of their electronics. During this period, a cottage hardware industry was created in a culture of imitation and reverse engineering practices, which, over time, resulted in different expressions of creativity: recycling, re-invention, and agility. Small companies that conducted business among themselves and worked together informally increased their manufacturing capacities and capabilities in order to target specific market segments that were not addressed by Western companies. These small companies collaborated throughout the entire process of the electronics value chain (design, sourcing, assembly, production testing, packaging and distribution) through an open source culture. This culture was very informal at the beginning (in other words, the culture of this region), and was strengthened by the arrival of the Western open source culture. Gradually, these small companies developed their own expertise, particularly in designing new products, and also developed a culture and quality control promoted by Western open source.

Starting in the early 1980s, Western firms took advantage of major reforms in China (gaige kaifant) to relocate manufacturing and to outsource production to the Shenzhen area in the Pearl River Delta (Al, 2012; Richet \& Ruffier, 2014). As this was China's first 'special economic zone' and was close to Hong Kong's legal and banking systems, it became an ideal location for electronics manufacturers (Margretta, 1998).

\subsection{The Shanzhai Cluster}

With the rapid growth of the components market in the 1990s, suppliers created standard components that were compatible with each other to accelerate their products' commercialization. The appearance of kits containing a set of parts and a manual (Chien \& Wang, 2010) enabled a host of small manufacturers to produce countless models of mobile phones at low cost. These phones are known as shanzhai (Keane \& Zhao, 2012; Liang, 2012), that is, midway between counterfeits and originals.

In the 1990s, some entrepreneurs took advantage of the city's geography, as it is close to Hong Kong and to parts suppliers, to counterfeit Nokia and Samsung handsets for the domestic market. The initial letters of Shenzhen (SZ) on the phones enabled them to circumvent national quality controls. Gradually, these phones came to be called shanzhai phones.

In 2004, the Taiwanese company MTK developed and sold its 'turnkey' processors at a low price, which 'democratized' telephone manufacturing. Gradually, as the shanzhai phone market grew, manufacturers turned away from simply copying others and started improving the materials and the features. In short, they realized they could innovate. They then acquired the capacity to make smartphones that were sold worldwide. Eighty million units, accounting for one-third of the phones made in China, were sold in 2011 (Liang, 2012). This shanzhai smartphone industry employed three million people in the Pearl Delta Region. In 2012, about 10,000 companies worked in this industry in the Shenzhen region (including approximately 2,000 phone 
manufacturers, 200 solution providers, 100 design firms, 1,500 national and regional buyers and 3,000 materials suppliers).

"Shanzhai phone manufacturers understood the needs of modest communities and so they made cheaper phones. They were successful thanks to these small communities, even though the shanzhai phone industry has had some problems."vi

Extreme competition led shanzhai phone makers to want to differentiate themselves, and thus they adopted an iterative innovation model used by small production units around Shenzhen.

Shanzhai phone manufacturers followed a different strategy than that of major manufacturers. Of course, they were able to incorporate all the latest technologies (for example, MP4 and television) at a lower cost thanks to MTK processors. But above all, they were successful because they were able to target each community of consumers differently, their manufacturing cycle was shorter than the big brands (six weeks), and almost seasonally they adapted to market demand with agility and flexibility. Shanzhai manufacturers need neither patents nor essential technologies, as they get the latter from the ecosystem leader, MTK. However, coopetition is ruthless and when a success story such as Xiaomi emerges from the mass of startups, their growth strategy comes to resemble that of well-established manufacturers: creating proprietary distribution networks, increasing $\mathrm{R} \& \mathrm{D}$, and 'rediscovering' intellectual property and its rights. In addition, research laboratories and telephone providers have developed thanks to support for innovation provided by the city of Shenzhen.

\subsection{Huaqiangbei, the Suppliers Cluster}

These clusters have grown thanks to the advantages of the Pearl Delta region: the international port of Hong Kong, half of all telephone factories in Dongguan, materials suppliers, distribution centres and sales platforms.

Products and components are sold in the Huaqiangbei district of Shenzhen, the world's largest electronics marketplace: a giant cluster consisting of a dense network of retailers and wholesalers. Huaqiangbei serves as a showcase both for international buyers and for the local industry, which it supplies with accessories, machines and components. In recent years, Huaqiangbei businesses have been feeling the effects of competition from the Internet and orders for equipment and components are mostly B2B. Mass producers of components have also set up marketing and sales services that directly rival retailers. These manufacturers' lack of technological expertise often prevents them from diversifying to more advanced technological fields.

Nick has worked in Huaqiangbei for several years as an exporter to India and Bangladesh:

"Let me explain the shanzhai business. The manufacturers invest zero in research, absolutely nothing. First, they buy design from design houses that will provide them with the hardware design and the software. Then it is all about competing on prices. Who[ever] knows the right guy to get cheaper parts and components, who can save one on this and two on that, who has faster machines, that guy will win the market. They all use [the] same package, same model name even, same everything, but the parts are getting cheaper really quickly. If you have a new product coming out, I know that the price will usually go down very quickly in a few days." 
Nick also explains the end of Huaqiangbei:

"All the businesses in Huaqiangbei are family businesses. They don't do much work outside the family. Shanzhai manufacturers don't take part in anything else: they don't design, they don't sell. People just focus on executing what they know in a better or cheap[er] way. Now that manufacturers are getting in[to] sales and marketing as well, nobody knows how to continue."

The industrial economic downturn prompted China to jettison the labourintensive model and instead to develop a more sophisticated manufacturing sector. The Chinese government announced a ten-year plan called Made in China 2025 (Zhongguo Zhizao 2025) to promote R\&D initiatives and nurture high-tech industries. The Chinese Premier has been to Shenzhen to visit Chaihuo, the city's hackerspace, where he pledged to support these new innovators who are at the forefront of China's modernization (PRC, 2015).

While the government's discourse at national level is that of modernizing factories from the old Made in China era, at the local level, in Guangdong province in particular, we observed that these small factories, instead of evolving, are closing and are being replaced by large companies offering a range of integrated services including design, sales, marketing and production. More specifically, in the field of telephony, five companies now have $60 \%$ of the mobile phone market of Chinese brands (excluding foreign brands).

Table 1. Market shares of Chinese smartphone manufacturers for $2^{\text {nd }}$ and $3^{\text {rd }}$ quarter $2015^{\text {vii }}$

\begin{tabular}{ccc}
\hline Companies & $\mathbf{2 0 1 5 / 3}$ & $\mathbf{2 0 1 5 / 2}$ \\
Huawei & $18.7 \%$ & $17.9 \%$ \\
Xiaomi & $12.7 \%$ & $14.0 \%$ \\
Lenovo & $12.7 \%$ & $12.5 \%$ \\
TCL & $10.4 \%$ & $9.7 \%$ \\
OPPO & $8.7 \%$ & $9.7 \%$ \\
Others & $36.8 \%$ & $36.2 \%$ \\
\hline
\end{tabular}

Source: Trendforce

\section{MODELS OF PLACES AND INNOVATION IN SHENZHEN}

The challenge for Shenzhen is to bring together the required skills in engineering, design and marketing, and existing manufacturing resources. Several hybrid models between the factory, the incubator, the co-working space, and the applied research centre have thus emerged around the city, resulting in highly innovative initiatives. 


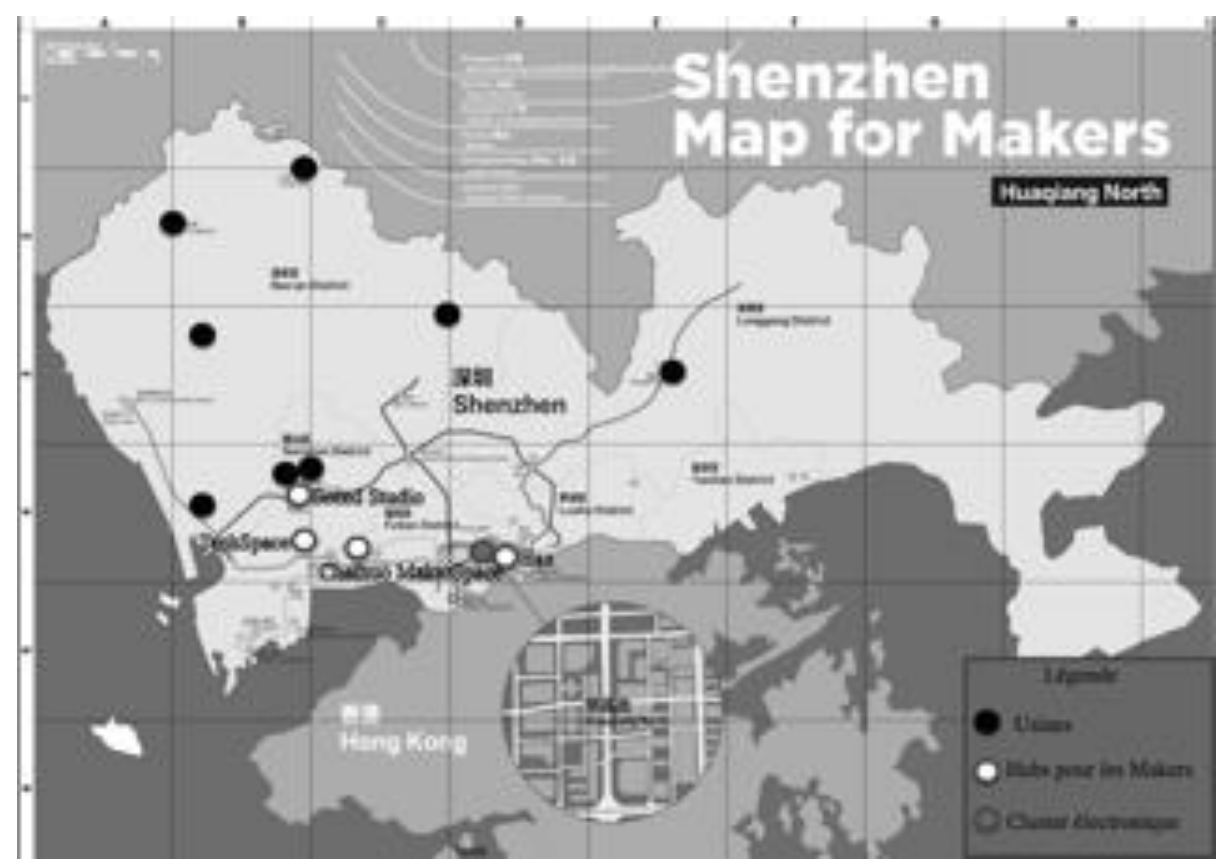

Figure 1. Map of the Makers' Ecosystem (source HaxLR8R, modified by the authors)

\subsection{Bao'an District: a Creative Industrial Cluster}

The Bao'an District is a cluster of factories specialized in manufacturing and assembling electronic products $(\mathrm{Ng}, 2011)$. Well-connected to transport networks and Shenzhen's underground subway, the Xixiang neighbourhood in Bao'an offers attractive rental rates for small businesses and a local government open to innovation proposals (Wang \& Ju, 2010).

Although little research has been done on this area, this largely industrial district offers several interesting case studies such as the F518 cluster, located at the centre of the district. This creative cluster caters to a specific demand: the design and production of connected devices. Based on a strict recruitment of firms by sector to ensure that the cluster has a portfolio of complementary competences - including design, electronics assembly, marketing services, and packaging - this cluster run by the local government offers a single point of contact. From the idea to the sale, the cluster meets customers' demands not only for design but also production: "We work with the hundreds of factories in the area. In recent years we have learned to know them well, and there are too many to name them all," explained Huang Xi, the manager. With over twenty products designed and manufactured, this cluster is constantly growing and is currently having new offices built to house more firms.

The majority of companies in the F518 cluster are subcontractors established in the Bao'an district. The manager of the cluster of companies in F518 explains:

"Let's say you want to make a phone. You can do everything at 518: industrial design (electronics), appearance. Any design can be made here. Then you can also do the packaging design. Once finished, you can also print in Bao'an... From idea to market, the businesses of 518 and the Bao'an district can do everything. This is what we call the supply chain model." 
Thus, cluster F518 groups together subcontractors whose services are mainly for factories wanting to design their own goods.

\section{$5.2 \quad$ From electronics design to production}

Another typical example is that of electronics designers who are gradually turning to production to become Small Electronics Manufacturers (SEM). We analyzed two such young firms, Mixtile and Cubietech, located at the heart of Chegongmiao, the neighbourhood occupied by most electronics designers. Both develop open-source development boards based on ARM processors, which can easily be used to produce a prototype. The founders of Mixtile, Eric Dong and Martin Liu, said that they chose open source to be able to focus on quality: "Designing hardware products is difficult... In traditional shanzhai, one has to move fast, very fast. Products are outdated immediately. With open source one can take more time and aim for quality, find good suppliers and develop a brand." In the case of Cubieboard, Mike Lee agrees, "We can develop new models progressively. If necessary, we can add on or take off functionalities to meet our customers' specific demands. Our Cubieboard 2 is used by a Singapore firm that designed a 3D printer." Located in the Bao'an district, Cubitech has access to the manufacturing resources of the surrounding firms, but the relationships are not always good. The founders of Mixtile have the same problem, as they explained, "The factories are dirty places and we don't want to go there. In fact, all the orders go via Internet." Both firms want to become better known and to acquire more clients thanks to their opensource products. They thus want to propose manufacturing services based on modified versions of their products, as well as design and customization services. Open source provides them with an opportunity to orient production towards a quality approach, to counter the bad image of 'Made in China,' and also to avoid the terrible pressure of the rhythm of shanzhai products:

"We have classmates in the shanzhai phone business, and it is very tough. For instance, he has to get his products out before August to make money, because the product lifecycle is 3 months maximum. If he doesn't [have] success, then it will [go] bankrupt. So he is always running, rushing, working... This is very hard work, very tiring. You can make a lot of money, but it is very dangerous. For instance, for a phone costing 100 yuan the designer maybe just get[s] 5 yuan, so he needs to produce a lot to make money. If it is good and on time, he can have [a] big return on his investment. If not, he is finished. For guys in [the] shanzhai business, a deadline really means dead!"

Based on open sourcing, the value proposition for these companies is quality design, based on the agile method (designs are sent to production via the Internet) and meeting demand.

\subsection{The incubator-factory: a step up from the 'fablab'}

The strong trend in information technology and innovation markets towards connected devices is naturally found in Shenzhen where resources abound. Several initiatives have sought to build bridges between the Californian innovation culture and Shenzhen's resources.

One of these, Seeeds Studio, founded in 2008 by former Intel employee Eric Pan, makes hardware models for open-source projects. It has an assembly 
line, a warehouse for inventory, a prototyping laboratory, and produces electronic objects for small and medium-sized series. Projects are often started with crowdfunding and then presented to Seeeds Studio as a prototype. Seeeds then takes care of industrial design, production, and shipping the products throughout the world. This fast-growing firm with over 180 employees helps start-ups scale up production from 'ten to 10,000 units.' It is located in the industrial zone of Liuxiandong in the Nanshan district, close to electronics producers and assemblers. Since 2011, it has also had a space called Chaihuo in the Overseas Chinese Town cluster, one of Shenzhen's key areas for designers and easily accessible for visitors. Every year, the firm also heads the organization of Shenzhen's Maker Fair, now a forum for encounters between these new Chinese industrial innovation models and the global community of innovators. Moreover, Seeeds Studio recently opened offices in California to facilitate access to its services for start-ups in connected devices, whose number is growing exponentially.

Another organization bringing Californian start-up culture to Shenzhen is HAXLR8R, an incubator for hardware projects located at the heart of Shenzhen's electronics market. Founded in 2011 by a group of Californian investors, it has created a project-development methodology called Lean Hardware, based essentially on using resources in Shenzhen to build the supply chains of the start-ups that are supported by HAXLR8R. The incubation program lasting 111 days covers all important points from production to export regulations and marketing strategies. The majority of projects are launched in a campaign on crowdfunding websites. Projects are also launched on Demo Day in San Francisco to take advantage of the presence of California's media. The early results of this incubator are highly encouraging, since the start-up success rate is over $85 \%$.

All of these places serve as nodes for an upstream funding network for the crowdfunding of open source projects and for producing small and medium series with a balanced cost model thanks to open sourcing. In fact, open sourcing enables companies to overcome certain problems: economies of scale vs economies of scope (the low-cost manufacturing of small production series is made possible by the reduced costs of design and manufacturing as a specific assembly of standard components is used); integration of production processes; and a better integration of the (re)design, production, and distribution phases.

\section{DISCUSSION: INNOVATION MODELS GROUNDED IN THE LOCAL CONTEXT AND PROMOTED BY OPEN MANAGEMENT PROCESSES}

The essential idea here is the role of open sourcing in the emergence of new value chains, driven by new kinds of 'fablabs' that manufacture in small and medium series. Open sourcing lowers the design and production costs and meets a variety of demands. It also enables an optimization of the design for agile production and re-designing due to the low cost of prototypes. Moreover, open sourcing facilitates the emergence of small companies specialized in complex electronic design (for the Internet of Things) for manufacturing distributed via the web. 
The birth of the "maker movement" has raised new questions on not only the creation of physical objects and devices connected to the Internet, but also more broadly on their role and their status throughout the urban fabric. How can new industrial dynamics driven by innovation be integrated into regions with different histories and identities? The city of Shenzhen offers one example of the appearance of new models that have directly grown out of its history and its regional characteristics. Here, the city's industrial past (capital, workforce, basic knowledge and recent knowledge) served as a base for building and attracting communities of innovators and for connecting with another land of innovation, California.

In California, the high-tech industry benefited extensively from opensource technologies and open innovation. They significantly accelerated the development of start-ups that went on to become large firms, especially in the Internet. In the Shenzhen ecosystem, the shanzhai open innovation model was a catalyst for the rapid development of a distributed manufacturing fabric, alongside the classic industrial model. This shanzhai model of multiple small companies specialized in manufacturing has since served as a resource for the growth of a high-tech industry that in many respects echoes the Fab City project. $^{\text {viii }}$

An important ingredient of the modernization of this industrial fabric making Shenzhen an innovative ecosystem has been open access to documentation on the technologies involved and their associated practices (open source). This documentation not only enables users to learn new, collaborative ways of working on a global scale, but also for manufacturers to guarantee the quality of their products validated by the user community and to benefit from this community as a marketing resource. Open innovation is at the centre of the modernization process because it accelerates business development and employee training. This culture of continuous learning and re-use of existing resources thus sometimes occurs in places that already exist, but which are now occupied by new actors who promote open innovation dynamics.

Thus, what is the 'maker' culture in China today? DIY has its places in the hackerspaces that emerged in Shenzhen, but everything happens around Seeeds Studio, the main physical 'enabler' and a physical third place helping U.S. do-it-yourselfers to manufacture and market their products. Seeeds Studio thus helps start-ups scale up to the level of industrial production.

This industrial network is also adept at shanzhai methods of absorbing/adapting/prototyping and testing new products very quickly. The shanzhai ecosystem became an innovative manufacturing system mainly because it bypasses the legal system of intellectual property. It is hardly surprising that this attitude toward copyright has received a favourable response in the maker movement.

Ultimately, the Chinese market blurs maker identity by contributing different qualities and values. For example, a 'pressy' button for phones financed by a crowdfunding campaign sold for $\$ 27$ in October 2013. Three months later, a speed button was sold for \$3; six months later, Xiaomi sold its version, Mikey, for $\$ 1$, before Qihho gave the smart button to developers for free. Here, they copy, they lower prices, and end up giving products away for free hoping to create an ecosystem around themselves, similar to MTK in Shanzhai (Liang, 2012). In China, the externalities and the DIY ecosystem are different from those in the West. WPG Holdings, one of the largest electronics distributors in Asia, makes Chinese versions open source. They design cards 
for factories and for designers that will be integrated into phones, tablets, watches, computers, etc. In another example, ATU designs 130 cards per year, free of charge, because what they mainly sell are the components of these cards, allowing them to attract creative companies (but not always very rich or necessarily Western) in order to design new cards.

This new form of open innovation follows the tradition of the shanzhai ecosystem headed by MTK and is similar to Western open source innovation, but should not be confused with it; this story is not simply that of Western empowerment.

\section{CONCLUSION}

As a region of innovation, Shenzhen is organized around two spaces whose borders are today barely permeable:

-an historical industrial cluster made of a myriad of small-scale manufacturing companies that have gradually increased their manufacturing capacity and capabilities. Their agility has been nourished by an 'illegal' and 'informal' open source culture. They are beginning to seize opportunities enabled by 'legal' open source, although that has not led to a change in their culture; and

-the new urban form that is the heart of the system: the incubator or accelerator for start-ups that includes prototyping as well as production. It is certainly here that the makers come (as a middle-ground space (Simon, 2009)), but they are essentially Western makers. HAXLR8R, for example, recruits in Europe and San Francisco. The makers come here because Shenzhen is the 'fablab' of the world (it has the heritage of the manufacturing city, of Made in China, etc.) and also because they have access to local resources. Yet, there is hardly any interaction with local manufacturing communities, who are still marked by the copycat culture (see the emblematic story of the 'pressy' button) and who are still very far from the ideals of sharing and of a "do it with others" approach.

This case study of electronics manufacturing in the Shenzhen area shows that open innovation models can support and accelerate the modernization of declining industrial sectors when these models are based on the economy and the industrial characteristics of the region. By examining the various models of innovation observed, we found that all were based on pre-existing technical and economic circumstances that they used in new ways to grow their business. Hence, the Californian innovation model that underpinned the development of the Internet and the Shenzhen innovation model in the hardware field cannot be applied or reproduced elsewhere, for they are intrinsically bound to the territories in which they emerged. The open innovation paradigm remains an emerging concept for technological changes and changes in manufacturing cultures that are rooted in local territories.

\section{ACKNOWLEDGEMENTS}

This work was supported by the French National Research Agency (ANR) [183.775 euros]. 


\section{REFERENCES}

Al, S. (2012). Factory Towns of South China: An Illustrated Guidebook. Hongkong: HK University Press.

Anderson, C. (2012). Makers: The New Industrial Revolution. New York: Crown Business.

Bathelt, H., \& Glückler, J. (2011). The Relational Economy: Geographies of Knowing and Learning. Oxford: Oxford University Press.

Bathelt, H., Malmberg, A., \& Maskell, P. (2004). "Clusters and Knowledge: Local Buzz, Global Pipelines and the Process of Knowledge Creation". Progress in human geography, 28(1), 31-56.

Blanchet, A., \& Gotman, A. (2007). "L'enquête Et Ses Méthodes: L'entretien [the Survey and Its Methods: Interview]". Sociologie [Sociology], 1-133.

Chesbrough, H. W. (2003). Open Innovation: The New Imperative for Creating and Profiting from Technology: Harvard Business Press.

Chesbrough, H. W., \& Bogers, M. (2014). "Explicating Open Innovation: Clarifying an Emerging Paradigm for Understanding Innovation. Ssrn Scholarly Paper Id 2427233". In Chesbrough, H., Vanhaverbeke, W., \& West, J. (Eds.), New Frontiers in Open Innovation (pp. 3-28). Oxford: Oxford University Press.

Chien, C.-F., \& Wang, J.-C. (2010). "Shanzai! Mediatek and The'white Box'handset Market". Harvard Business School Technology \& Operations Mgt. Unit Case No. 610-081. Retrieved from http://ssrn.com/abstract=2041963

Corrado, C., Haskel, J., Jona-Lasinio, C., \& Iommi, M. (2014). "Ict, R\&D and Non-R\&D Intangible Capital: Complementary Relations and Industry Productivity Growth in European Countries". Paper presented at the 3rd World KLEMS Conference (May 19-20, 2014), Tokyo.

Dale, K., \& Burrell, G. (2008). The Spaces of Organisation and the Organisation of Space: Power, Identity and Materiality at Work. Basingstoke: Palgrave Macmillan.

Dumay, J., \& Cuganesan, S. (2011). "Making Sense of Intellectual Capital Complexity: Measuring through Narrative". Journal of Human Resource Costing \& Accounting, 15(1), 24-49.

Dyer, J. H., \& Nobeoka, K. (2000). "Creating and Managing a High-Performance KnowledgeSharing Network: The Toyota Case". Strategic management journal, 21(3), 345-367.

Garnier, C. (2014). "Fablabs: De La Cohabitation À La Coopération, Etude D'artilect, Fablab Toulousain [Fablabs: Coexistence to Cooperation, Survey of Artilect, Toulouse Fablab]". (Master), Université de Toulouse, France.

Gershenfeld, N. (2005). Fab: The Coming Revolution on Your Desktop - from Personal Computers to Personal Fabrication. Cambridge: Basic Books.

Keane, M., \& Zhao, E. J. (2012). "Renegades on the Frontier of Innovation: The Shanzhai Grassroots Communities of Shenzhen in China's Creative Economy". Eurasian Geography and Economics, 53(2), 216-230.

Kogut, B. (2000). "The Network as Knowledge: Generative Rules and the Emergence of Structure". Strategic management journal, 21(3), 405-425.

Li, D. (2014). "The New Shanzhai: Democratizing Innovation in China". SJTU ParisTech Review. Retrieved from http://www.paristechreview.com/2014/12/24/shanzhaiinnovation-china/

Liang, S. (2012). "L'analyse Des Telephones Shanzhai [Analysis of Shanzhai Phones]". (Master), University de Toulouse, France.

Lindtner, S. (2014). "Hackerspaces and the Internet of Things in China: How Makers Are Reinventing Industrial Production, Innovation, and the Self". China Information, 28(2), 145167.

Lindtner, S. (2015). "Hacking with Chinese Characteristics the Promises of the Maker Movement against China's Manufacturing Culture". Science, Technology \& Human Values, $1-26$.

Margretta, J. (1998). "Fast, Global, and Entrepreneurial: Supply Chain Management, Hong Kong Style". Harvard business review, 76(5), 102-114.

Nahapiet, J., \& Ghoshal, S. (1998). "Social Capital, Intellectual Capital, and the Organizational Advantage". Academy of management review, 23(2), 242-266.

Oldenburg, R. (1989). The Great Good Place. New York: Paragon House.

Renaud, C., Fernandez, V., \& Puel, G. (2015). "Changing the Culture of Innovation in Shanghai: Open Innovation Spaces". Paper presented at the Third conference of Geography of innovation. 
Richet, X., \& Ruffier, J. (2014). "Ci-Gît L'industrialisation Mondiale: Fin Du Rôle Sociétal De La Fabrication Industrielle [Here Lies the Global Industrialization : End of the Societal Role of Industrial Manufacturing]". Autrepart, 1, 3-26.

Simon, L. (2009). "Underground, Upperground Et Middle-Ground: Les Collectifs Créatifs Et La Capacité Créative De La Ville". Management international/Gestiòn Internacional/International Management, 13, 37-51.

Van Marrewijk, A., \& Yanow, D. (2010). Organizational Spaces: Rematerializing the Workaday World. Cheltenham: Edward Elgar Publishers.

Wang, Q., \& Ju, Z.-q. (2010). "The Innovation of Outsourcing Pubilc Services by Governments — a Case Study of the Sub-District of Xixiang in Shenzhen, Guangdong". Scientific Decision Making, 4, 31-40.

Warf, B., \& Arias, S. (2008). The Spatial Turn: Interdisciplinary Perspectives. Abingdon: Routledge.

West, J., Salter, A., Vanhaverbeke, W., \& Chesbrough, H. (2014). "Open Innovation: The Next Decade". Research Policy, 43(5), 805-811.

' Shanzhai, literally meaning 'mountain village,' refers to counterfeit or coarse imitations of big brand name goods by artisans or small Chinese companies, particularly in electronics.

ii Interview with Tomas Diez, FabLab Barcelona's manager, in 2014.

iii In the sense of territory, region and geography.

iv Three months of fieldwork in the Research Department for Electronics of the China Unicom telephone company, which resulted in a research report (Liang, 2012). All the data in Section 3 can be found in that report.

${ }^{v}$ All of the data is housed on a server of the French National Research Agency (ANR) as open data. As part of the larger research project funded by the French National Research Agency (http://www.agence-nationale-recherche.fr/?Project=ANR-13-SOIN-0006). Other 'third place' models of innovation were examined in other regions of China that corresponded to different socio-economic configurations.

${ }^{\text {vi }}$ Excerpt from the interview of the Head of the Electronic Products Research Team at Shenzhen.

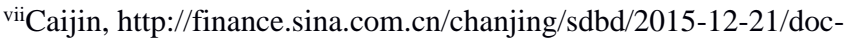

ifxmttme6044290.shtml, accessed 2 December 2012.

viii http://fab.city/, available 2016/01/22.

\section{APPENDIX}

For each space, tasks are:

a. draw a map of the space

b. quick inventory of key machines/objects (with pictures if possible)

c. interview of owner, manager or community manager

d. ask for datasets (previous surveys, mailing lists, social media accounts, etc.)

Table 2. List of interviews

\begin{tabular}{|l|l|l|l|}
\hline Name & Role & Activity & Time \\
\hline Momi Han & Manager & Electronics maker & $1 \mathrm{~h} 30$ \\
Martin Liu & Founder & Electronics maker & $1 \mathrm{~h} 30$ \\
Joseph Wang & Founder & Electronics maker & $2 \mathrm{~h}$ \\
Qu Hang & PR executive & Bitcoin & $1 \mathrm{~h}$ \\
Huang Xi & Parti leader & CIC Manager & $1 \mathrm{~h}$ \\
C. Eberweiser & Founder & Incubator & $1 \mathrm{~h}$ \\
\hline
\end{tabular}




\begin{tabular}{|l|l|l|l|}
\hline Cao Meiying & OpenPlatform & Web business & $1 \mathrm{~h}$ \\
C. Valenza & Founder & FPGA & $1 \mathrm{~h}$ \\
Eric Dong & Founder & Electronics & $1 \mathrm{~h} 30$ \\
Fu Na & Urban Planner & Urban Planning & $1 \mathrm{~h} 30$ \\
Tat Lam & Founder & Community & $1 \mathrm{~h} 30$ \\
Nik & Export reseller & Electronics gross sales & $2 \mathrm{~h}$ \\
Momi Han & Manager & Electronics maker & $1 \mathrm{~h}$ \\
Mayling C & Sales & LED maker & $1 \mathrm{~h}$ \\
Jack Lee & Founder & Hardware startup & $1 \mathrm{~h}$ \\
Lafier Kong & Manager & Fablab & $0 \mathrm{~h} 45$ \\
J. Gadikian & Founder & Hardware startup & $1 \mathrm{~h} 30$ \\
Shu Wen & International lead & Training and education & $2 \mathrm{~h}$ \\
Si Jinling & Program head & Training and education & $1 \mathrm{~h}$ \\
Shirley & Founder & Professional & $1 \mathrm{~h}$ \\
\hline & $\mathbf{1 7}$ people & Users & $1 \mathrm{~h}$ each \\
\hline
\end{tabular}

\section{Interview questions}

1) THE SPACE/ORGANIZATION: the management of their organization (15 $\mathrm{min})$

a. Quick story of the space

b. What are the key assets that allow your space/organization to be sustainable?

c. What are the most important objects of your space?

d. What is the most important online tool you use? How does it contribute to running the space? Why is it so important?

e. Do you know about open bill, open date, agile management...?

2) THE NETWORKS: The networks of innovation in China

a. What are the networks supporting your activities?

b. Are they more informal or institutional? Governments?

c. What is the scope of those networks? International? Local? National?

d. Which sort of resources do they provide? Visibility? Funding? Structure?

e. How are partnerships with HK? US? EU?

f. TRENDS: Open Innovation in Manufacturing

g. Do you know about "open innovation"/"open source"?

h. How is it perceived in Shenzhen? And in China? Are people aware of it?

i. How does it relate to existing manufacturing/entrepreneurship culture here?

j. What advantages/drawbacks do you identify in "open" models ?

$\mathrm{k}$. What are the management/organizational trends you see emerging in Shenzhen now? Bigger organizations? Smaller/distributed? Local/international? 